\title{
Sacubitril/valsartan in therapy of hypertension
}

\author{
Jerzy Głuszek', Teresa Kosicka² \\ ${ }^{1}$ State Higher Vocational School in Kalisz \\ ${ }^{2}$ Department of Hypertension, University of Medical Sciences Poznań
}

\begin{abstract}
In recent years a new very promising drug was introduced for the treatment of chronic heart failure. This drug, sacubitril/valsartan, prevents the clinical progression of surviving patients with heart failure more effectively than enalapril and it reduces the need for hospitalization by more than $20 \%$. At the same time it has been shown that it reduces blood pressure particularly in patients with essential hypertension. This drug is an inhibitor of neprilysin, an enzyme that degrades natriuretic factors. Natriuretic factors (ANP, BNP, CNP) increase diuresis and natriuresis, reduce the activity of the sympathetic system, relax the blood vessels and inhibit fibrosis. Several studies have shown that sacubitril/valsartan therapy more significantly reduces blood pressure in patients with salt-sensitive or refractory to treatment hypertension than is observed with valsartan or amlodipine. Furthermore, beneficial effects of this drug on central blood pressure and renal function have been demonstrated in patients with chronic renal failure. More rarely than enalapril it leads to hyperkalaemia in patients treated simultaneously with mineralocorticoid receptor inhibitors. Sacubitril/valsartan is the first representative of a new class of drugs that inhibit neprilysin, which probably in the future will be frequently used in hypertension.

key words: hypertension, natriuretic factors, sacubitril/valsartan
\end{abstract}

Arterial Hypertens. 2017, vol. 21, no. 2, pages: 99-104

DOI: $10.5603 / A H .2017 .0013$

In the last 30 years, no new class of antihypertensive drugs has been included into the treatment of hypertension. For many years, the guidelines of Societies of Hypertension have been invariably listing the same classes as the drugs of first choice. Although new formulations characterized by fewer side effects (e.g. lercanidipin or zofenopril) did appear on the Polish pharmaceutical market, they belong to the already known calcium antagonists and ACE inhibitors. Progress in the treatment of hypertension involves skilful combination of the already known antihypertensive drugs of different classes, which increases the effectiveness of the treatment and reduces the occurrence of side effects.

Recently, a new drug, effective in the treatment of heart failure has been introduced into cardiology [1] The drug is called sacubitril/valsartan - (Entresto
Novartis, already available in Poland). It deserves special attention also from hypertensiologists, as it significantly reduces blood pressure. Neprilysin inhibitor included in the drug inhibits the degradation of the biologically active natriuretic factors that increase diuresis and blood vessel relaxation. Neprilysin (also called neutral endopeptidase - NEP) is a membrane-bound metalloendopeptidase and is widely distribute $\mathrm{d}$ in the body tissues, especially in the brush border of the proximal renal tubule [2]. The primary function of this compound is based on enzymatic degradation of natriuretic factors, as well as endothelin-1, substance $P$, gastrin and beta-amyloid protein [3]. Currently, 3 natriuretic peptides are known, i.e. atrial natriuretic factor (ANP), brain natriuretic factor $(\mathrm{BNP})$ and $\mathrm{C}$-type natriuretic factor (CNP) [4]. Natriuretic factor type A and type B is

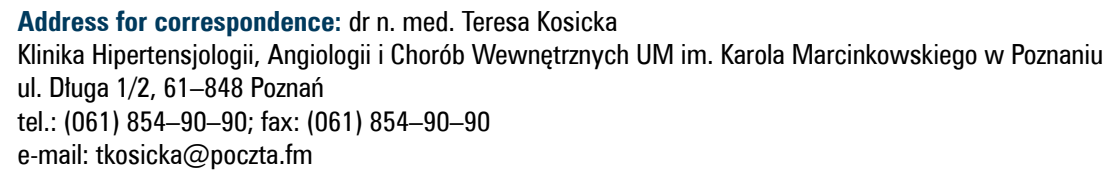


synthesized primarily in cardiomyocytes in response to myocardial tension. C-type natriuretic factor is synthesized primarily in endothelial cells. B-type is also synthesized by cardiac fibroblasts and prevents myocardial fibrosis [2]. All of these natriuretic factors are active via a second messenger, i.e. cyclic guanosine monophosphate-3-5 (cGMP), potentiate diuresis and natriuresis, dilate blood vessels and, in addition, reduce the tone of the sympathetic system and suppresses fibrosis [5, 6]. Recent studies indicate that natriuretic factors influence the growth and proliferation of endothelial cells by reducing the impact of such atherogenic factors as cell proliferation, apoptosis, angiogenesis and inflammation. More and more data support the fact that hypertension and heart failure are accompanied by a shortage of natriuretic factors [2]. High level of BNP in blood serum in response to fluid overload is insufficient because of impaired activity of these compounds in heart failure. Studies indicate that the hypertension reveals impaired process of BNP synthesis from precursor pro-BNP, leading to reduced biological activity of this hormone [2].

The biologically active ANP dilates the blood vessels supplying blood to the renal glomeruli (afferent vessels) and narrows efferent vessels, which increases the glomerular filtration and diuresis [7]. In addition, this compound elicits relaxation of mesangial cells and increases the filtration surface. The animals lacking the gene responsible for the pro-ANP synthesis develop sodium sensitive hypertension and have a tendency for heart hypertrophy, stroke and kidney damage [8]. The reintroduction of this gene reduces the blood pressure and prevents organ damage [9].

The concentration of neprilysin (also called neutral endopeptidase) significantly correlates with the severity of heart failure and mortality [10]. For this reason, attempts have been made to synthesize neprilysin inhibitor and to use it as a medicine reducing the risk of these complications. Candoxatrilat was one of the first of these compounds. This drug increased levels of natriuretic factors (ANP, BNP $\mathrm{CNP}$ ) and diuresis, but it did not lower blood pressure probably through the simultaneous increase in endothelin and angiotensin-II [11]. Another drug, omapatrilat, is a combination of neprilysin and ACE inhibitor. This drug reduced cardiovascular mortality in the IMPRESS study, but has not been approved for routine use by the US Food and Drug Administration because of the high risk of developing angioedema, which were observed in the OCTAVE and OVERTURE studies [12]. Only a combination of neprilysin inhibitor with valsartan significantly reduced side effects, at the same time showing high efficacy in patients with chronic heart failure and, as shown in recent studies, also in hypertension.

First, in experimental rats of SHR breed (spontaneously developing sodium-sensitive hypertension), sacubitril/valsartan caused a greater decrease in blood pressure compared to valsartan [13]. It also increased renal excretion of sodium and inhibited the activity of the sympathetic nervous system. Furthermore, a substantial reduction of adverse remodelling of the heart and reduction of inflammation and improvement of endothelial function in comparison with valsartan were observed [13]. Mura et al. demonstrated that sacubitril not only greatly increases the excretion of ANP and BNP but also decreases the aldosterone synthesis in tissue culture of the adrenal cortex cells [14].

Sacubitril, neprilysin inhibitor is a prodrug marked as AHU377. After oral intake, the drug is rapidly metabolized to the active neprilysin inhibitor marked as LBQ657 [15]. The maximum concentration of the latter compound is observed after 2 hours and the half-life is 11.5 hours. Maximum concentrations of valsartan in serum and its half-life are very similar -1.5 hours and 10 hours, respectively. These data indicate that the best dosage of LCZ696 is its administration two times a day. After administration of the sacubitril/valsartan we can observe the increase in the blood concentration of the cyclic guanosine monophosphate and renin and angiotensin II in response to administration of valsartan [15]. Gan et al. evaluated the effect of age and gender on the pharmacokinetics of the drug administered at a dose of $400 \mathrm{mg} /$ day in 19 healthy men and 17 women. Eighteen persons were aged $18-45$ years and 18 respondents were aged 65 and older. The halflife of the drug was 30\% longer in the elderly; the maximum concentration of drug in the blood was similar in both groups. The maximum concentration of valsartan was 30\% higher in the elderly. All tested pharmacological parameters were the same in males and in females. The authors conclude that the gender and age of the respondents do not play a significant role in the dosage of the drug [16].

The PARADIGM-HF study involving 8000 patients with heart failure revealed that the therapy with sacubitril/valsartan resulted not only in statistically significant improvement of heart failure and a reduction in mortality, but also had a slight decrease in blood pressure amounting to an average of $9.3 / 4.9 \mathrm{mmHg}$ after 12 weeks of therapy [1]. In contrast, patients treated only with valsartan had a significantly lower level $(\mathrm{p}<0.05)$ decrease in blood pressure $(2.9 / 2.1 \mathrm{mmHg})$. After 36 weeks of treatment, analogous decreases were $7.5 / 5.1 \mathrm{mmHg}$ 


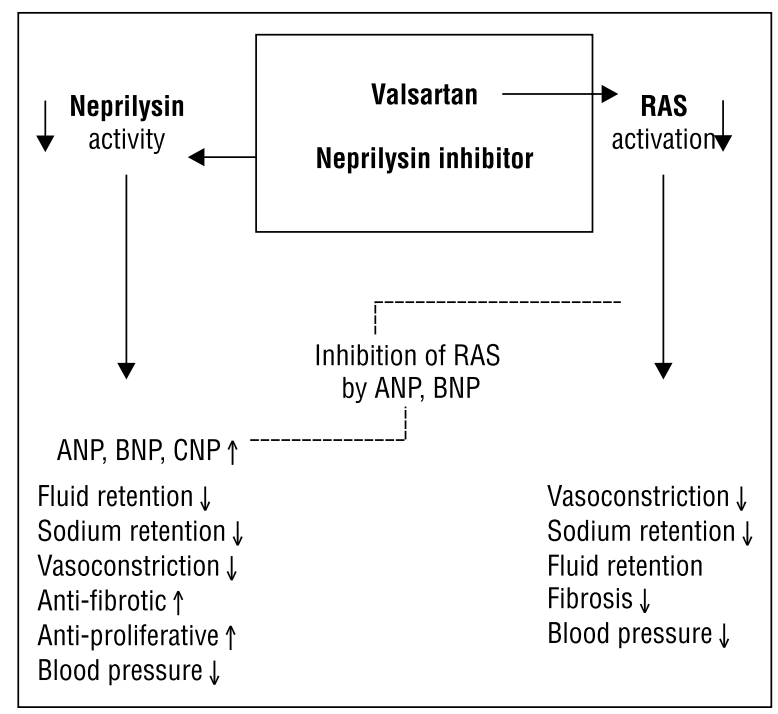

Figure 1. Mechanism of action of sacubitril/walsartan

and $1.5 / 0.3 \mathrm{mmHg}$. It was noted that in patients with normal blood pressure sacubitril/valsartan did not considerably lower blood pressure, and pressure drops were the highest with the highest initial pressures. The multicentre PARAMETER study involving 454 patients aged over 60 years with hypertension and pulse pressure above $60 \mathrm{mmHg}$ compared the effects of sacubitril/valsartan $400 \mathrm{mg} /$ day with olmesartan $80 \mathrm{mg} /$ day on central aortic pressure [17]. After 12 weeks of this therapy it has been shown that sacubitril/valsartan more significantly reduced systolic central pressure (by $12.6 \mathrm{mmHg}$ ) compared to olmesartan that reduced systolic central pressure only by $8.9 \mathrm{mmHg}(\mathrm{p}<0.01)$. Systolic blood pressure measured on the shoulders dropped by 13.7 and 9.9 $\mathrm{mmHg}$, respectively. There was also more significant reduction of pulse pressure after the administration of sacubitril/valsartan [17].

Wang et al. compared the diuresis and natriuresis under sacubitril/valsartan and valsartan in $72 \mathrm{pa}$ tients with sodium sensitive hypertension [18]. This randomized, double-blind, cross-over study diagnosed sodium sensitive hypertension, if the mean arterial pressure (MAP) increased at least by $10 \%$ after switching from diet containing $50 \mathrm{mmol}$ of sodium per day to $320 \mathrm{mmol}$ of sodium per day (both diets used for seven days). Patients were treated for 28 days with sacubitril/valsartan at a dose of $400 \mathrm{mg} /$ day or valsartan $320 \mathrm{mg} /$ day. Diuresis was examined on the first day after 6 and 24 hours after administration of the study drug, and then on 28th day of therapy, using the same procedure. On the first day, the two measurements showed that sacubitril/valsartan caused higher increase in diuresis and natriuresis than valsartan. However, after 28 days, the diuresis and natriuresis were similar in sacubitril/ /valsartan and valsartan groups. These data show that the investigational drug only initially increases the renal excretion of sodium and the effect weakens and disappears after a month of treatment [18].

Japanese researchers, Kario et al., administered sacubitril to 32 patients with severe hypertension, so far untreated or not taking medication for four weeks [19]. The inclusion criterion was systolic blood pressure higher than $180 \mathrm{~m} \mathrm{Hg}$ or diastolic blood pressure higher than $110 \mathrm{mmHg}$. Sacubitril starting dose was $200 \mathrm{mg} /$ day. If blood pressure was not reduced below $160 / 100 \mathrm{mmHg}$, the dose was increased to $400 \mathrm{mg} /$ day. If the blood pressure after 4 weeks did not decrease below $140 / 90 \mathrm{mmHg}$, other antihypertensive agents were included, with the exception of ACE inhibitors and sartans. The mean baseline systolic pressure was $173.4 \mathrm{mmHg}$ and diastolic pressure was $112.4 \mathrm{mmHg}$. After a week of treatment, the systolic blood pressure decreased by 18.7 and diastolic blood pressure by $10.3 \mathrm{mmHg}$. After 4 weeks of therapy with sacubitril it was 150.3 and diastolic was $98.5 \mathrm{mmHg}$. After 8 weeks of combination therapy, blood pressure values were respectively $138.1 / 90.3 \mathrm{mmHg}$. The drug was well tolerated, with only some patients reporting rhinitis and pharyngitis [19].

In a large group of 389 patients with hypertension, Kario et al. evaluated the effect of different doses of sacubitril and placebo on blood pressure measured by ABPM. Each dose of sacubitril, $100 \mathrm{mg}, 200 \mathrm{mg}$ and $400 \mathrm{mg} / \mathrm{day}$, more significantly decreased the measurement of clinical blood pressure compared to placebo ( $\mathrm{p}<0.0001)$. ABPM also revealed blood pressure drop, both during the day and the night. There were no serious side effects, particularly no patient reported angioedema [20].

The largest group of hypertensive patients $(\mathrm{n}=$ 1328) treated with sacubitril/valsartan was analysed by Ruilope et al. [21]. These authors compared the effect of this drug in a dose of 100, 200 and $400 \mathrm{mg} /$ /day, with the effects of valsartan 80,160, and 320 $\mathrm{mg} /$ day and with placebo on diastolic pressure. After 8 weeks of the study, the drug slightly but statistically significantly decreased diastolic blood pressure more than valsartan. Three patients experienced severe side effects; however, they turned out to be not related to the tested drug [21].

The longest, lasting 52 weeks, study on the efficacy and safety of LCZ696 was conducted on a group of 341 patients with hypertension by Supasyndh et al. [22]. Patients whose blood pressure was not normalized after a dose of $400 \mathrm{mg}$ two times a day of sacubitril/valsartan also received amlodipine and 
hydrochlorothiazide. After 52 weeks, blood pressure was reduced by $24.7 / 16.2 \mathrm{mmHg}$. Seventy-five percent of patients had a reduction of pressure below $140 / 90 \mathrm{mmHg} ; 18.2 \%$ of patients experienced symptoms of rhinitis and nasopharyngitis, $8.8 \%$ of patients complained of dizziness. One patient had angioedema [22].

Already quoted Wang compared in another study the efficacy and safety of coadministration of sacubitril/valsartan with amlodipine $5 \mathrm{mg}$ and amlodipine $5 \mathrm{mg}$ alone in patients with hypertension in whom the dose of amlodipine alone did not prove to be an effective drug [23]. After eight weeks of this therapy, in 165 patients on combined treatment with sacubitril/valsartan and amlodipine 24-hour blood pressure decreased by $13 \mathrm{mmHg}$ and in 160 consecutive patients on amlodipine alone blood pressure decreased by $0.8 \mathrm{mmHg}$. Pulse pressure decreased by 5.8 vs $0.6 \mathrm{mmHg}$. Adverse reactions occurred with equal frequency in both treatment groups.

Hypertension often accompanies chronic kidney disease (CKD). According to Konta et al., 58\% of patients with chronic renal disease have hypertension and in individuals with normal renal function the prevalence of hypertension was $42 \%$ [2]. Furthermore, in CKD patients, hypertension is often resistant to antihypertensive therapy and in only $22 \%$ it is possible to achieve a normalization of blood pressure, in contrast to the patients without kidney function impairment in whom the correct blood pressure is achieved in 44\% [24]. Ito at al. assessed the efficacy and safety of sacubitril/valsartan in patients with hypertension and renal failure [25]. The initial blood pressure of the patients was 151.6/86.9 $\mathrm{mmHg}$, GFR was lower than $60 \mathrm{~mL} / \mathrm{min}$ and in $21 \%$ of patients it ranged from 15 to $30 \mathrm{~mL} / \mathrm{min}$. After 8 weeks of treatment with an initial dose of 200 and $400 \mathrm{mg}$ of the target dose of sacubitril/valsartan, blood pressure decreased by $20.5 / 8.3 \mathrm{mmHg}$. Blood pressure drop was the highest during the first two weeks, slightly lower in the subsequent 14 days, and then the values of blood pressure did not change until the end of the study. The geometric mean of urinary protein decreased by $15.1 \%$. The proportion of patients with well-controlled blood pressure also increased [25]. No significant changes in levels of creatinine, urea and potassium in the blood serum were observed. The authors of this study speculated that the beneficial effect in patients with severe renal failure is due to the increase of blood flow in the renal medulla. There were also no serious side effects; only one patient discontinued the drug because of headaches. None of the patients complained about the dizziness and angioedema.
The aim of the study of Voors' et al. was to assess the impact of sacubitril/valsartan on renal parameters in patients with heart failure with preserved systolic function [26]. The study included 301 patients who were randomly assigned to therapy with sacubitril/ /valsartan or valsartan alone. All patients were subjected to the evaluation of creatinine and cystatin $C$ levels in serum, glomerular filtration rate and urinary albumin excretion at baseline, after 12 and after 36 weeks of treatment. Significant deterioration in renal function was defined as an increase in the concentration of serum creatinine of $0.3 \mathrm{mg} \%$ and/or $>25 \%$. At baseline, the glomerular filtration rate (GFR) was $65.4 \pm 20.4 \mathrm{~mL} / \mathrm{min}$. The decrease in GFR was lower in patients receiving sacubitril/valsartan than in those on valsartan $(1.5 \mathrm{v} 5.2 \mathrm{~mL} / \mathrm{min}$, respectively; $\mathrm{p}=0.002)$. Significant deterioration in renal function occurred in $12 \%$ of patients in sacubitril/valsar$\tan$ group and in $18 \%$ of patients in valsartan group. After 36 weeks of therapy, the geometric mean of urinary protein excretion increased from 2.4 to $2.9 \mathrm{mg} /$ $/ \mathrm{mmol}$ in sacubitril group and did not change in patients treated with valsartan (from 2.1 to $2 \mathrm{mg} / \mathrm{mmol}$ of creatinine; $p=0.016$ ). Thus, renal parameters were much better after treatment with sacubitril compared with valsartan, with the exception of increased excretion of protein in the urine. This last parameter is considered an important predictor; an increase in urinary protein excretion is usually an expression of deterioration of renal function [26]. However, some authors believe that increased proteinuria is an expression of increased permeability of the glomerulus under the influence of natriuretic factors and is not related to a deterioration of renal function [27-29]. Meta-analysis performed by Bodey et al. showed that omapatrilat (IMPRES, OVERTURE) and sacubitril/ /valsartan (PARADIGM-HF and PARAMOUNT) reduce by $32 \%$ the risk of kidney damage compared with a convertase inhibitor or a sartan [30]. The UK HARP III trial was planned in order to explain the impact of neprilysin inhibitor on kidney function in patients with renal failure [31].

Moreover, sacubitril/valsartan is characterized by favourable effects on insulin resistance. Jordan et al. administered sacubitril/valsartan $400 \mathrm{mg} /$ day or amlodipine $10 \mathrm{mg} /$ day for 8 weeks in patients with hypertension and obesity [32]. Insulin sensitivity was assessed by euglycaemic clamp. The therapy with sacubitril/valsartan significantly increased insulin sensitivity, while treatment with amlodipine had no effect on its level [32]. Diuretics and beta-blockers, often used for high blood pressure, increase insulin resistance and promote the development of diabetes in patients treated in this way. Therapy with sacubi- 
tril/valsartan is devoid of these hazards and is likely to prevent the development of type 2 diabetes. Patients with heart failure and patients with hypertension are often treated with the antagonist of mineralocorticoid receptor (e.g. spironolactone, eplerenone) and the inhibitors of angiotensin convertase. This can often lead to dangerous hyperkalaemia. Desai et al. compared the incidence of this complication (potassium above $6 \mathrm{mmol} / \mathrm{L}$ ) in patients treated in this way with or without add-on treatment with sacubitril/ /valsartan [33]. Hyperkalaemia occurred significantly less frequently in patients treated with additional sacubitril/valsartan (HR 1.37; $\mathrm{p}=0.02$ ).

Some researchers have raised concerns that sacubitril/valsartan inhibits enzymatic degradation of beta amyloid, which can lead to accelerated progression of Alzheimer's disease [34]. Although the PARADIGM-HF trial showed no significantly higher prevalence of dementia in patients treated with sacubitril/valsartan compared to treatment with enalapril $(0.36 \%$ vs $0.29 \%$ ), further long-term studies are necessary to clarify whether this drug may indeed pose a threat to patients.

As the above review of the literature shows, sacubitril/valsartan is not only likely to be successfully used in patients with heart failure, but it will also enrich the arsenal of drugs for hypertension. Sacubitril/valsartan is the first drug inhibiting neprilysin and we can expect that in the near future there will be more drugs from this group that will be even more effective in the treatment of hypertension.

\section{References}

1. Packer M, McMurray JJV, Desai AS, et al. PARADIGM-HF Investigators and Coordinators. Angiotensin receptor neprilysin inhibition compared with enalapril on the risk of clinical progression in surviving patients with heart failure. Circulation. 2015; 131(1): 54-61, doi: 10.1161/CIRCULATIONAHA.114.013748, indexed in Pubmed: 25403646.

2. Kobalava $Z$. The role of natriuretic peptides in the pathogenesis of cardiovascular diseases. J Hypertens. 2016; 34(Suppl 1 ISH2016 Abstract Book): e377.

3. Benigni A, Zoja C, Zatelli C, et al. Vasopeptidase inhibitor restores the balance of vasoactive hormones in progressive nephropathy. Kidney Int. 2004; 66(5): 1959-1965, doi: 10.1111/j.15231755.2004.00982.x, indexed in Pubmed: 15496167.

4. Mangiafico S, Costello-Boerrigter LC, Andersen IA, et al. Neutral endopeptidase inhibition and the natriuretic peptide system: an evolving strategy in cardiovascular therapeutics. Eur Heart J. 2013; 34(12): 886-893c, doi: 10.1093/eurheartj/ehs262, indexed in Pubmed: 22942338.

5. Gardner DG, Chen S, Glenn DJ, et al. Molecular biology of the natriuretic peptide system: implications for physiology and hypertension. Hypertension. 2007; 49(3): 419-426, doi: 10.1161/01. HYP.0000258532.07418.fa, indexed in Pubmed: 17283251.

6. Potter LR, Abbey-Hosch S, Dickey DM. Natriuretic peptides, their receptors, and cyclic guanosine monophosphate-dependent signaling functions. Endocr Rev. 2006; 27(1): 47-72, doi: 10.1210/er.20050014, indexed in Pubmed: 16291870.
7. Voors AA, Gori M, Liu LCY, et al. PARAMOUNT Investigators. Renal effects of the angiotensin receptor neprilysin inhibitor LCZ696 in patients with heart failure and preserved ejection fraction. Eur J Heart Fail. 2015; 17(5): 510-517, doi: 10.1002/ejhf.232, indexed in Pubmed: 25657064.

8. Melo LG, Veress AT, Chong CK, et al. Salt-sensitive hypertension in ANP knockout mice: potential role of abnormal plasma renin activity. Am J Physiol. 1998; 274(1 Pt 2): R255-R261, indexed in Pubmed: 9458926.

9. Lin KF, Chao J, Chao L. Atrial natriuretic peptide gene delivery reduces stroke-induced mortality rate in Dahl salt-sensitive rats. Hypertension. 1999; 33(1 Pt 2): 219-224, indexed in Pubmed: 9931108.

10. Bayés-Genís A, Barallat J, Galán A, et al. Soluble neprilysin is predictive of cardiovascular death and heart failure hospitalization in heart failure patients. J Am Coll Cardiol. 2015; 65(7): 657-665, doi: 10.1016/j.jacc.2014.11.048, indexed in Pubmed: 25677426.

11. McDowell G, Nicholls DP. The endopeptidase inhibitor, candoxatril, and its therapeutic potential in the treatment of chronic cardiac failure in man. Expert Opin Investig Drugs. 1999; 8(1): 79-84, doi: 10.1517/13543784.8.1.79, indexed in Pubmed: 15992061.

12. Kostis JB, Packer M, Black HR, et al. Omapatrilat and enalapril in patients with hypertension: the Omapatrilat Cardiovascular Treatment vs. Enalapril (OCTAVE) trial. Am J Hypertens. 2004; 17(2): 103-111, indexed in Pubmed: 14751650.

13. Kusaka H, Sueta D, Koibuchi N, et al. LCZ696, Angiotensin II Receptor-Neprilysin Inhibitor, Ameliorates High-Salt-Induced Hypertension and Cardiovascular Injury More Than Valsartan Alone. Am J Hypertens. 2015; 28(12): 1409-1417, doi: 10.1093/ajh/ hpv015, indexed in Pubmed: 25762811.

14. Miura SI, Suematsu Y, Matsuo Y, et al. The angiotensin II type 1 receptor-neprilysin inhibitor LCZ696 blocked aldosterone synthesis in a human adrenocortical cell line. Hypertens Res. 2016; 39(11): 758-763, doi: 10.1038/hr.2016.72, indexed in Pubmed: 27334058.

15. Gu J, Noe A, Chandra P, et al. Pharmacokinetics and pharmacodynamics of LCZ696, a novel dual-acting angiotensin receptor-neprilysin inhibitor (ARNi). J Clin Pharmacol. 2010; 50(4): 401-414, doi: 10.1177/0091270009343932, indexed in Pubmed: 19934029.

16. Gan Lu, Langenickel T, Petruck J, et al. Effects of age and sex on the pharmacokinetics of LCZ696, an angiotensin receptor neprilysin inhibitor. J Clin Pharmacol. 2016; 56(1): 78-86, doi: 10.1002/ jcph.571, indexed in Pubmed: 26073563.

17. Williams B, Cockcroft JR, Kario K, et al. Effects of Sacubitril/ Valsartan Versus Olmesartan on Central Hemodynamics in the Elderly With Systolic Hypertension: The PARAMETER Study. Hypertension. 2017; 69(3): 411-420, doi: 10.1161/HYPERTENSIONAHA.116.08556, indexed in Pubmed: 28093466.

18. Wang TD, Tan RS, Lee H, et al. Treatment with LCZ696 compared to AT-1 receptor blockade is associated with non-sustained increases of natriuresis and diuresis in Asian patients with salt-sensitive hypertension. J Hypertens. 2015; 33 Suppl 1: e124, doi: 10.1097/01. hjh.0000467685.39554.d4, indexed in Pubmed: 26102721.

19. Kario K, Tamaki Y, Okino N, et al. LCZ696, a First-in-Class Angiotensin Receptor-Neprilysin Inhibitor: The First Clinical Experience in Patients With Severe Hypertension. J Clin Hypertens (Greenwich). 2016; 18(4): 308-314, doi: 10.1111/jch.12667, indexed in Pubmed: 26402918.

20. Kario K, Sun N, Chiang FT, et al. Efficacy and safety of LCZ696, a first-in-class angiotensin receptor neprilysin inhibitor, in Asian patients with hypertension: a randomized, double-blind, placebo-controlled study. Hypertension. 2014; 63(4): 698-705, doi: 10.1161/HYPERTENSIONAHA.113.02002, indexed in Pubmed: 24446062.

21. Ruilope LM, Dukat A, Böhm M, et al. Blood-pressure reduction with LCZ696, a novel dual-acting inhibitor of the angiotensin II receptor and neprilysin: a randomised, double-blind, placebo-controlled, active comparator study. Lancet. 2010; 375(9722): 1255-1266, doi: 10.1016/S0140-6736(09)61966-8, indexed in Pubmed: 20236700

22. Supasyndh O, Sun N, Kario K, et al. Long-term (52-week) safety and efficacy of Sacubitril/valsartan in Asian patients with hypertension. 
Hypertens Res. 2017; 40(5): 472-476, doi: 10.1038/hr.2016.151, indexed in Pubmed: 27853163.

23. Wang JG, Yukisada K, Sibulo A, et al. Efficacy and safety of sacubitril/valsartan (LCZ696) add-on to amlodipine in Asian patients with systolic hypertension uncontrolled with amlodipine monotherapy. J Hypertens. 2017; 35(4): 877-885, doi: $10.1097 /$ HJH.0000000000001219, indexed in Pubmed: 28030431.

24. Konta T, Ikeda A, Ichikawa K, et al. Blood pressure control in a Japanese population with chronic kidney disease: a baseline survey of a nationwide cohort. Am J Hypertens. 2012; 25(3): 342-347, doi: 10.1038/ajh.2011.217, indexed in Pubmed: 22089103.

25. Ito S, Satoh M, Tamaki Y, et al. Safety and efficacy of LCZ696, a first-in-class angiotensin receptor neprilysin inhibitor, in Japanese patients with hypertension and renal dysfunction. Hypertens Res. 2015; 38(4): 269-275, doi: 10.1038/hr.2015.1, indexed in Pubmed: 25693859 .

26. Voors AA, Gori M, Liu LCY, et al. PARAMOUNT Investigators. Renal effects of the angiotensin receptor neprilysin inhibitor LCZ696 in patients with heart failure and preserved ejection fraction. Eur J Heart Fail. 2015; 17(5): 510-517, doi: 10.1002/ejhf.232, indexed in Pubmed: 25657064.

27. Lofton CE, Newman WH, Currie MG. Atrial natriuretic peptide regulation of endothelial permeability is mediated by cGMP. Biochem Biophys Res Commun. 1990; 172(2): 793-799, indexed in Pubmed: 2173580.
28. Battle T, Michel JB, Corman B. Effect of atrial natriuretic factor on the water permeability of endothelial cells. Biochem Biophys Res Commun. 1992; 185(1): 386-391, indexed in Pubmed: 1318044.

29. Huxley VH, Tucker VL, Verburg KM, et al. Increased capillary hydraulic conductivity induced by atrial natriuretic peptide. Circ Res. 1987; 60(2): 304-307, indexed in Pubmed: 2952366.

30. Bodey F, Hopper I, Krum H. Neprilysin inhibitors preserve renal function in heart failure. Int J Cardiol. 2015; 179: 329-330, doi: 10.1016/j.ijcard.2014.11.059, indexed in Pubmed: 25464479.

31. Judge P, Haynes R, Landray MJ, et al. Neprilysin inhibition in chronic kidney disease. Nephrol Dial Transplant. 2015; 30(5): 738-743, doi: 10.1093/ndt/gfu269, indexed in Pubmed: 25140014.

32. Jordan J, Stinkens R, Jax T, et al. Improved Insulin Sensitivity With Angiotensin Receptor Neprilysin Inhibition in Individuals With Obesity and Hypertension. Clin Pharmacol Ther. 2017; 101(2): 254-263, doi: $10.1002 /$ cpt.455, indexed in Pubmed: 27542885.

33. Desai AS, Vardeny O, Claggett B, et al. Reduced Risk of Hyperkalemia During Treatment of Heart Failure With Mineralocorticoid Receptor Antagonists by Use of Sacubitril/Valsartan Compared With Enalapril: A Secondary Analysis of the PARADIGM-HF Trial. JAMA Cardiol. 2017; 2(1): 79-85, doi: 10.1001/jamacardio.2016.4733, indexed in Pubmed: 27842179.

34. Vodovar N, Paquet C, Mebazaa A, et al. Neprilysin, cardiovascular, and Alzheimer's diseases: the therapeutic split? Eur Heart J. 2015; 36(15): $902-$ 905, doi: 10.1093/eurheartj/ehv015, indexed in Pubmed: 25636748. 